\title{
Da educação do juízo de gosto*
}

ロ<smiles>[2H]</smiles>

iscorre sobre a necessidade do ensino das artes e da sua história na educação. Visa educar o juízo de gosto para assim instrumentar o estudante a identificar a beleza como expressão da totalidade humana. Corrobora a noção de que a formação do cidadão, do artista e do ser emancipado são interdependentes. Define os termos capazes de conferir disciplinaridade ao ensino das artes, ao reconhecer na estética o campo disciplinar que tem como objeto de estudo a práxis humana, quando esta visa objetivar, através da obra de arte, a conjugação das dimensões subjetiva e objetiva, individuais e sociais, ou seja, o ser na totalidade. Situa as categorias citadas: julgamento de gosto, totalidade, belo, autonomia, estética. Sugere um roteiro de leitura da obra de arte inferido das premissas conceituais.

\section{Matheus Gorovitz}

Palavras-Chave: estética; belo; gosto; totalidade; autonomia; cidadania.

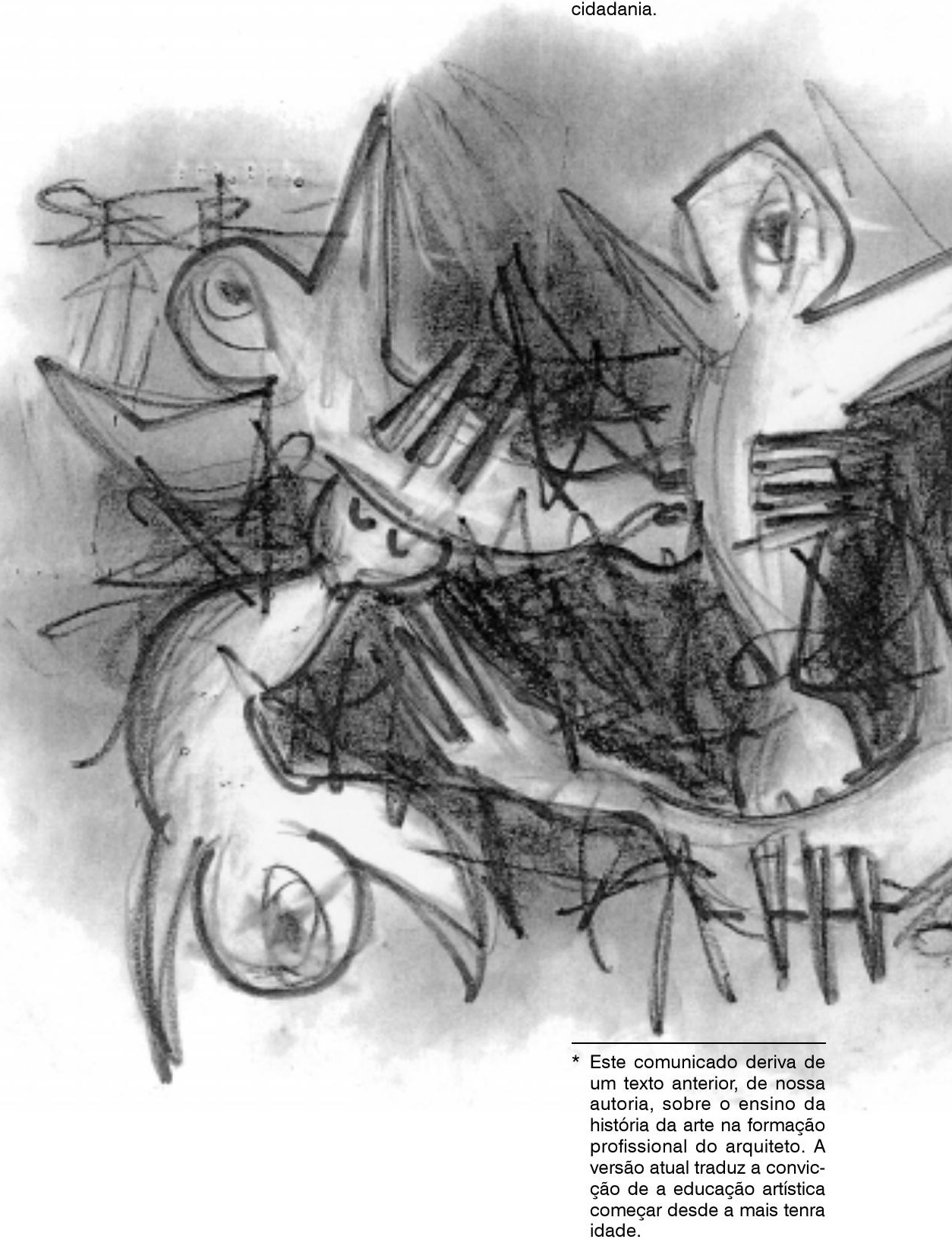


I

Se se quiser gozar da arte, deve-se ser um homem artisticamente educado.

Karl Marx. Manuscritos EconômicoFilosóficos

Este trabalho discorre sobre a necessidade do ensino das artes e da sua história. Visa, ao instrumentar o estudante, a identificar a beleza como expressão da autonomia humana, permitir que exerça, através do juízo de gosto, a condição de ser emancipado. Admitindo, na senda do pensamento iluminista de Kant, a volição e autodeterminação como prerrogativas propriamente humanas, infere, na atividade artística, um modo de reafirmar esta essência.

A diferença, segundo Kant, entre o homem e o resto da natureza animal, inanimada ou vegetal é que esta pertence ao reino da causalidade, seguem rigorosamente algum esquema pré ordenado de causa e efeito, enquanto que o homem é livre para escolher o que ele quer. A vontade é o que distingue seres humanos de outros objetos na natureza (Berlin, 1999, p. 70).

Um ser só se considera autônomo quando é senhor de si mesmo, e só é senhor de si quando deve a si mesmo seu modo de existência. Um homem que vive graças ao outro, se considera a si mesmo um ser dependente (...) a vida tem necessariamente o fundamento fora de si mesma, quando não é minha própria criação (Marx, 1978, p. 14).

\section{Julgamento de gosto}

Arbitrar sobre o belo identificando as condições que o qualificam (seja propondo ou reconhecendo o belo na obra de arte) requer, na prática didática, educar o juízo de gosto. Tal modo de ajuizar implica assumir uma decisão na ausência de uma razão prática ou ainda de uma razão lógica. O juízo de gosto não tem como parâmetro de avaliação nenhum valor preestabelecido, tem, isto sim, como referencial, o trabalho humano plasmado no acervo de obras de arte. $\mathrm{O}$ objeto não é aferido pelo valor prático-utilitário - a capacidade de satisfazer uma necessidade particular predeterminada -, nem se alicerça em valores estabelecidos a priori, conceituais, éticos, ou os que, sedimentados pela tradição, passam a ser consensuais. Diferencia-se, ainda, do discernimento fundamentado, cognitiva ou teoricamente, quando são pré-conceitos, conhecimentos adquiridos ou a argumentação lógica, que asseguram a certeza do julgamento justo. É a interação das capacitações racionais, intelectivas, volitivas e sensoriais que engendra o juízo de gosto e constitui por isto, como ação autônoma e autodeterminada, uma práxis, no sentido que lhe atribui Marx:

\begin{abstract}
Atividade livre, universal, criativa e autocriativa, por meio da qual o homem cria (faz, produz) e transforma (conforma) o seu mundo humano e histórico e a si mesmo; atividade específica ao homem, que o torna basicamente diferente de todos os outros seres (Bottomore,1988, p. 292).
\end{abstract}

A práxis é o ato que realiza a unidade entre o sujeito e o objeto (...) nela coincidem as determinações do pensamento e o desenvolver-se da história. Por isso a práxis é a consciência da totalidade e sua realização. A consciência não precede a ação, pelo contrário, ela funda-se no ato (Bobbio, 1992, p. 989).

Ao promover a interação das dimensões subjetivas e objetivas e exercitar tais prerrogativas, a obra de arte faculta ao indivíduo, seja no instante da concepção ou da apreciação, objetivar sua totalidade - a totalidade das capacitações individuais. Plenitude efetivamente objetivada pela consciência da exterioridade da obra, pois "Só em objetos reais, sensíveis, pode [o sujeito] exteriorizar sua vida" (Marx, 1978, p. 40).

\section{Totalidade}

A totalidade subentende o conjunto de necessidades e possibilidades humanas exercidas de modo integrado, quando o 
lado sensível e o racional da consciência não comparecem fragmentados - o sujeito é autoconsciente, seja na plenitude ou na adversidade da condição existencial. $O$ contrário desta condição é a alienação, no sentido atribuído por Marx:

Ação pela qual (ou estado no qual) um indivíduo, um grupo, uma instituição ou uma sociedade se tornam (ou permanecem) alheios, estranhos, enfim, alienados aos resultados ou produtos de sua própria atividade (e à atividade ela mesma), e/ou à natureza na qual vivem, e/ou a outros seres humanos, e - além de, e através de - também a si mesmos (às suas possibilidades humanas constituídas historicamente) (Bottomore, 1988, p. 5).

O ser emancipado, cujo comportamento não é heteronomicamente determinado ou predeterminado, mas sim, que determina os parâmetros de sua ação e nesta determinação se autodetermina, implica a articulação das esferas subjetivas e objetivas - da sensibilidade e da racionalidade, da dupla condição de indivíduo particular (motivado pela razão prática e pela subjetividade), e de ser genérico (motivado pela vocação social e mediado pela universalidade do pensamento objetivo - lógico e cognitivo), pois, conforme postula Marx: "É somente na elaboração de um mundo objetivo que o homem se afirma como ser social" (Marx, 1978, p. 12).

\section{Belo}

A mediação entre o universo subjetivo e o objetivo se faz pelo conceito de belo; ao afirmar, mediante o juízo de gosto que algo é belo, quero que meu sentimento (particular e subjetivo) possa ser compartiIhado coletivamente; por isto, associo um conceito (objetivo e universal) à singularidade subjetiva. Atribuo um valor universal a um sentimento afetivo particular.

O juízo estético envolve uma contradição, ou antinomia, pois embora exprima uma experiência do sujeito, da sua sensibilidade particular, pretende que a significação dessa experiência seja comunicável aos outros e encontre ressonância universal. Eis porque Kant nos diz a propósito da quantidade do juízo, que "belo é o que agrada universalmente sem conceito" (...).
No juízo estético, portanto, verifica-se o acordo, a harmonia, ou a síntese, entre a sensibilidade e a inteligência, o particular e o geral (Corbisier, 1987, p. 67-68).

No conceito de belo, é sublinhada a consciência do ser como ser social, pois ao valer-se de um conceito (universal) que se manifesta como fenômeno, pode, então, se comunicar. Comunicabilidade igualmente possível no plano do cotidiano, na linguagem prosaica quando prevalecem valores individuais e subjetivos ("Maria é bela"), ou ainda no discurso lógico ou ético que almeja, ao contrário, a universalidade, expressão não-tributária de aspectos subjetivos e particulares ("É belo morrer pela pátria"). No primeiro caso, o sujeito objetiva a consciência da sua individualidade (particular e subjetiva), no segundo, a consciência de sociabilidade (universal e objetiva).

\section{Autonomia}

A idéia de "ser autônomo" é homóloga à de "belo" como expressão autônoma: "Proporção que uma parte mantém com outras partes e com o todo" (Tatarkiewicz, 1995, p. 122).

A síntese entre o conteúdo (sujeito autônomo) e a forma (objeto autônomo) adjetivada como beleza e objetivada pela obra de arte é uma práxis e, enquanto tal, tem um sentido volitivo e libertário: promover a consciência da autonomia e da liberdade, esta entendida como consciência de necessidades e possibilidades objetivas historicamente constituídas, e como corolário, o sentido de responsabilidade móvel da cidadania.

A liberdade é a consciência simultânea das circunstâncias existentes e das ações que, suscitadas por tais circunstâncias, nos permitem ultrapassá-las (Chauí, 1994, p. 362).

Ao contrário dos processos naturais ou necessários, e das ações que resultam da coação e da violência, as ações humanas consideradas livres são intencionais, visam determinado fim, têm motivo que as explica e incluem um projeto, bem como a decisão de um agente responsável. A intencionalidade é a característica fundamental do comportamento consciente e livre. A circunstância de ter feito, 
estar fazendo ou pretender fazer alguma coisa intencionalmente define a liberdade e a responsabilidade da conduta humana (...) Ao reconhecer-se responsável pelo que pratica, o sujeito se reconhece, também, como agente livre ou causa de tais atos, excluindo-os conseqüentemente, do domínio da natureza ou da necessidade (...) A liberdade, como observa Hegel, deixa de ser arbitrária e adquire sentido, ou se torna racional, quando duas vontades, defrontando-se a respeito de um litígio sobre propriedade, por exemplo, reconhecem-se mutuamente, dando origem a uma vontade comum que se traduz no acordo ou contrato, que prefigura o Estado, forma suprema do espírito objetivo (Corbisier, 1987, p. 160).

O caráter libertário, subjacente à conjugação entre a esfera do objetivo e do subjetivo, contido no juízo de gosto e manifestado graças à existência objetiva da obra de arte, é apontado por Rousseau: "Liberdade é obedecer a uma lei por nós mesmos imposta" (apud Bobbio, 1992, p.712).

Compete ao artista, valendo-se da obra de arte como fator promotor da autoconsciência e autodeterminação (consciência de si), da consciência da cidadania (consciência dos outros), contribuir para a construção da cidade democrática:

Somente no estado social, subjetivismo e objetivismo, espiritualismo e materialismo, atividade e passividade deixam de ser contrários e perdem com isso seu modo de existência como tais contrários (...) sua própria sensibilidade só através do outro existe para ele como sensibilidade humana (Marx, 1978, p. 13-14).

Ser senhor de si - isto é - autônomo - é ser capaz de philia - isto é, reciprocidade, de relação intersubjetiva como coexistência e não-violência - é o núcleo da vida ética. Como disse Epicuro, "a justiça não existe por si própria, mas encontra-se sempre nas relações recíprocas, em qualquer tempo e lugar em que exista entre os humanos o pacto de não causar nem sofrer danos (Chauí, 1994, p. 367).

A polis grega, fundamentada na noção de isonomia - "participação igual de todos os cidadãos no exercício do poder" (Vernant, 1981, p. 56) - ilustra a noção de autonomia auferida pela relação das partes entre si (na obra: dos componentes formais, e no ser: das dimensões humanas). A proporção - relação entre as partes - pressupõe o reconhecimento da relevância de cada parte na formação do todo, da autonomia de cada unidade do sistema formal e de cada indivíduo na sociedade.

A noção essencial é, de fato, a de proporção; a cidade forma um conjunto organizado, um cosmos harmoniosamente constituído se cada um de seus componentes situa-se em seu local e possui a porção de poder que lhe é conferida em função de suas virtudes próprias (Vernant, 1981, p. 90).

A autonomia inerente ao julgamento de gosto, com o qual nos apropriamos da obra-de-arte, tem um corolário: exclui toda forma de autoritarismo: "Nenhum privilégio, nenhuma autocracia de qualquer espécie pode ser tolerada onde impera o gosto" (Schiller, 1982, p. 217).

\section{Estética}

As premissas acima suscitam a seguinte questão: podemos qualificar disciplinarmente o ensino da arte? Tal questão se depara com um paradoxo: o conhecimento disciplinar visa ao universal e ao necessário, não ao particular e ao contingente; é, portanto, estruturado pelo raciocínio lógico traduzido em conceitos universais e objetivos, que não podem se alterar em presença de juízos subjetivos. Como, então, qualificar disciplinarmente um objeto de estudo (a obra-de-arte) tributário de um modo de interação particular, sensível e subjetivo, com prerrogativas fundamentalmente individuais?

Admitir a obra de arte como objeto de conhecimento disciplinar pressupõe, como condição preliminar e necessária, sua existência objetiva, ou seja, algo passível de ser definido, algo sobre o qual posso formular conceitos mediante os quais reconheço, em artefatos particulares, a condição geral de ser obra de arte, permitindo, assim, como corolário, ajuizar sobre o belo enquanto categoria passível de definição conceitual:

Inclusão de um objeto (símbolo ou função) em uma classe, pela determinação das condições sob as quais o objeto por definir se 
iguala a qualquer elemento da referida classe (Dicionário Eletrônico Aurélio).

O conhecimento só é científico na medida em que constitui um sistema, uma unidade ou um todo lógico, no qual os juízos (qualquer enunciado científico é um juízo) se acham vinculados uns aos outros pela coerência ou pela racionalidade do método. Verifica-se, assim, que a "cientificidade" da ciência consiste não só na estrutura de seus conhecimentos, que devem ser universais e necessários, mas também na unificação metódica desses conhecimentos em uma totalidade coerente (Corbisier, 1987, p. 208).

A questão pode ser equacionada ao se considerar as duas principais vertentes que se confrontam em busca de uma definição de obra de arte: a que se distingue por considerar os fatores que qualificam o belo como intrínsecos, inerentes ao objeto (à obra de arte), ou extrínsecos, inerentes às condições de percepção do sujeito.

$\mathrm{Na}$ primeira vertente, os atributos do belo serão identificados nas peculiaridades internas à obra; na segunda, o belo é tributário de fatores extra-artísticos, de dois modos:

- na esteira da tradição platônica, como essência ideal: um belo-em-si, independente das obras individuais, comparecendo como termo de referência e padrão universal, noção assim ilustrada no diálogo de Hípias Maior:

Sócrates: - Então, o que é a beleza? Hípias: - Ou seja, você está me perguntando que coisa é bela?

Sócrates: - Não exatamente, Hípias. Pergunto o que é o Belo.

- na tradição empirista, como tributário da experiência e da subjetividade. A expressão "gosto não se discute" denuncia um relativismo assim fundamentado por Hume: "A beleza não é uma qualidade em si, existe meramente na mente de quem contempla e cada mente percebe uma beleza diferente" (Hume, 1984, p. 318).

A possibilidade de conciliação dessas abordagens norteou as premissas de estruturação didática: admitir a Estética como campo disciplinar que tem como objeto de estudo a práxis humana, quando esta visa objetivar, através da obra de arte, a conjugação das dimensões subjetiva e objeti- va, intelectuais e sensíveis, individuais e sociais, ou seja, o ser na totalidade.

A categoria da totalidade, desenvolvida pela filosofia clássica alemã (Kant, Hegel, Marx) marca a evolução, na história do pensamento filosófico, da metafísica para a concepção dialética. Representa a superação da dicotomia sujeito/objeto na qual se alicerça todo o pensamento metafísico.

Totalidade subentende a indissociabilidade das esferas do subjetivo e do objetivo. Sujeito e objeto são, na concepção dialética, antitéticos e complementares, interagindo num processo do qual a obra de arte emerge como uma das sínteses possíveis. Síntese ao privilegiar seja o universo sensorial, o racional, o volitivo e o cognitivo denuncia o equilíbrio, tensão ou conflito destas capacitações do ser.

Lúcio Costa e Artigas traduzem assim, cada um a seu modo, o conceito de totalidade:

O que caracteriza a obra de arte é precisamente esta eterna presença, na coisa, daquela carga de amor e de saber que, um dia, a configurou (Costa, 1980, p. 5).

A consciência humana, com seu lado sensível e com seu lado racional, não tem sido convenientemente interpretada como um inteiro, mas como a soma de duas metades. Aos artistas, principalmente, compete conhecer esta dicotomia para ultrapassá-la (Artigas, 1981, p. 49).

Ao se apropriar do objeto de um modo estético, o ser humano se liberta de ser heteronomicamente determinado. Quando o ser imprime a universalidade de sua essência (sua práxis) em um objeto e torna este objeto "objetivo", o objeto não pode determinar heteronomicamente seu ser, torna-se, isto sim, uma expressão da força do ser humano. Objetividade e liberdade são termos correlativos. De fato, o homem só se relaciona consigo no objeto estético, isto é, sua liberdade, sua autoidentidade.

Considerando-se que só em objetos reais e concretos pode o ser manifestar sua vida (Marx), a estética fundamentase na homologia entre a autonomia da obra de arte e a autonomia do ser (a coerência interna da forma e a concordância entre esta forma e o conteúdo a ser expresso). 


\section{Roteiro de leitura analítica da obra de arte}

A premissa de que a obra de arte fornece (por constituir-se uma entidade autosuficiente - uma totalidade em si) a um observador atento, lógico, racional e sensível os elementos necessários e suficientes para sua decodificação, e o objetivo de desenvolver o juízo de gosto com vistas à formação do artista nortearam o parâmetro pedagógico adotado: o estudo da arte e de sua história não precedido de esquema conceitual fundamentado de antemão, mas sim construído no confronto entre as capacitações sensíveis e intelectivas dos estudantes com as obras de arte. Tal confronto, monitorado por um roteiro de apreciação e descrição de obras de arte, visa engendrar uma consciência ampliada:

1ㅇ) enquanto obra em si: consciência da existência física da obra (passível de ser mensurada com precisão objetiva);

2o) enquanto imagem criada pelo sujeito: consciência de si, das faculdades e prerrogativas racionais, sensíveis, volitivas e intelectivas, despertadas pela obra no sujeito (incomensuráveis);

3ㅇ) enquanto modalidade de linguagem: consciência de si como ser social, consciência engendrada pela existência de um meio de comunicar-se.

Esse roteiro pode assim ser percorrido:

$$
\text { Objeto-em-si }
$$

Descrever os componentes plásticos (físico-espaciais), visualizáveis e tangíveis (graças à sua exterioridade objetiva), cada um deles separadamente e integrados num sistema.

$$
\text { Objeto-para-si }
$$

Descrever a imagem produzida pela obra no sujeito, considerando o fato de que os elementos identificados e descritos na sua exterioridade objetiva motivam capacitações individuais do sujeito - a sensibilidade, a racionalidade e a inteligibilidade (seja em igual medida, ou priorizando uma ou outra dessas prerrogativas).

$$
\text { Objeto-em-si-e-para-si }
$$

Considerada como forma significativa - como suporte material de signifi- cados, a obra de arte constitui uma modalidade de linguagem. Categoria indissociável da consciência - uma das formas de objetivação da consciência a linguagem artística objetiva a condição social sem desconsiderar a individualidade - é instrumento pelo qual satisfaz sua necessidade de intercâmbio com os outros homens e, assim, reconhece-se como ser social; é o que entendemos da afirmação de Marx (1977, p. 43-44):

\begin{abstract}
A linguagem é tão antiga como a consciência - a linguagem é a consciência real, prática, que existe para os outros homens e, portanto, também para mim mesmo, e a linguagem nasce, como a consciência, da carência, da necessidade de intercâmbio entre os homens.
\end{abstract}

Enquanto objeto inteligível, a obra de arte confere ao sujeito consciência de si (enquanto indivíduo) como ser social porque tem no fazer artístico um recurso um significante - para comunicar seus significados e, portanto, se comunicar. Como decorrência da consciência da exterioridade do objeto (obra), apreende que o mundo real e a consciência não estão divorciados.

Um ser que não tenha sua natureza fora de si não é um ser natural, não faz parte da essência da natureza. Um ser que não é, por sua vez, objeto para um terceiro ser não tem nenhum ser como objeto seu, isto é, não se comporta objetivamente, seu ser não é objetivo (Marx, 1977, p. 41).

A comunicação pode ainda ser através da linguagem coloquial ou prosaica quando pessoal e subjetiva; através do discurso lógico quando a descrição, objetiva e universal visa à transmissão de conhecimento decodificado em noções e conceitos. Referimo-nos acima à linguagem artística ou poética quando a necessidade é a de expressar o ser na sua totalidade.

O roteiro sugerido descreve as obras como expressão da totalidade e corresponde à estrutura do real entendida como processo dialético. Cartesianamente dividido em partes, os três momentos são, em verdade, um só, sintetizados pela obra; tal caráter analítico não deve, sobretudo, motivar um procedimento mecânico, inibindo, assim, o intercâmbio espontâneo com a obra. 


\section{Critérios e procedimentos didáticos}

- Pressuposta a obra como totalidade (estrutura significativa), visamos estimular a leitura das obras sem nenhuma forma de mediação e, assim, ampliar a consciência das prerrogativas da sensibilidade, da inteligibilidade e da racionalidade. Para isto, a leitura não deve ser precedida de informação teórica preliminar; tal interferência iria de encontro ao objetivo de fomentar a confiança do estudante no seu julgamento de gosto - a faculdade de julgar o belo. Descartamos, como decorrência, a hipótese de o aprendizado das artes ser tributário de conhecimento teórico preliminar como instrumentação considerada necessária na leitura da obra de arte, venha ele sob a forma de conceitos, informações culturais, históricas, ou ainda metodológicas, adquiridas seja por leitura, seja pelo magistério de aulas expositivas. A conceituação deve comparecer no instante em que ela for necessária, como resultado das inquietações dos estudantes, em função das questões por eles suscitadas, ou para aferir hipóteses de interpretação aventadas. Por falta de confiança na sua faculdade de julgar, no seu julgamento de gosto, o estudante apela espontaneamente para as referências bibliográficas. Essas informações devem vir a posteriori, como forma de verificação; cabe, então, investigar a vida dos artistas, as relações sociais, as condições materiais da época e as idéias dominantes.

- A leitura comparativa de obras (ou projetos) evidencia os propósitos plásticos adotados. Tal leitura deverá sempre confrontar obras, não apenas de um mesmo período diferindo nas intenções, mas igualmente as que antecedem ou precedem o período estudado. A comparação de projetos de arquitetura com outras modalidades de manifestação artística é não apenas estimulante, como serve para reiterar o entendimento das obras. Igualmente frutífero é situar a linguagem poética, distinguindo-a da prosaica e da científica, ao assinalar a tendência da obra de arte em se aproximar ora de uma, ora de outra modalidade de linguagem.

- A experiência mostrou que, em face da insegurança em avaliar e julgar os aspectos formais, o estudante tende a comentar os aspectos episódicos e anedóticos (em se tratando de arquitetura, os técnicos e funcionais). Sem reprimir esta postura, devemos mostrar que ela sempre espelha valores pré-conceituados (identificação de elementos de um universo de vivências acumuladas e sedimentadas pela tradição); é conveniente insistir, isto sim, em identificar a coerência, promovida pela obra, entre os elementos plásticos e os narrativos entre forma e conteúdo.

- Enquanto objeto-em-si, a descrição deve considerar a obra como um conjunto de sinais plásticos estruturados como sistema, o reconhecimento da família desses sinais, e a homologia estabelecida entre eles permite agrupá-los em categorias (Wolfflin sugere uma taxonomia em sua obra Princípios Fundamentais da História da Arte).

- Na descrição da obra como objeto-para-si, em função das dificuldades do estudante, podemos organizar metodologicamente a vivência subjetiva introduzindo progressivamente termos com os quais ele possa expressar seus sentimentos e pensamentos, parâmetros tais como: intelectual/sensorial/racional; pitoresco/sublime; simbólico/alegórico; ideal/contextual; intenção/tradição ou categorias como clássico/romântico.

- A descrição da obra como objetoem-si-e-para-si é o momento de reconhecer os significados gerais - culturais, históricos e coletivos - que a obra expressa e com os quais está comprometida. O estudante será estimulado a reconhecer a postura do artista em relação aos valores vigentes, reiterando-os ou contestando-os, podendo, então, identificar as dimensões valorizadas nesse contexto: afetivas e intelectivas, sensíveis e racionais, individuais e coletivas, bem como a predominância ou o equilíbrio delas (é nesta etapa, e a posteriori, que a consulta bibliográfica se faz mais significativa). Vale agora introduzir termos como liberdade/necessidade; individualidade/coletividade; intenção/tradição; cultura/natureza; fenomênico/ numênico; autônomo/heterônomo; direito adquirido/direito de constituir; ideal/ conjuntural. Os termos mencionados, embora dicotômicos, não são excludentes, pois na relação de totalidade nenhuma dimensão é hegemônica; ocorrerá, isto sim, a valorização de uma delas, que a obra de arte irá privilegiar.

- Da noção da totalidade, enquanto síntese entre forma e conteúdo, decorre 
um corolário: categorias estéticas nãonormativas que não privilegiam determinadas manifestações artísticas em detrimento de outras. No confronto de obras e projetos, a apreciação deverá ser isenta de qualquer forma de julgamento maniqueísta; a análise será sempre mais rica se restringir-se a identificar disposições plásticas diferenciadas e a coerência desses elementos formais entre si e com os conteúdos expressos. Admitir de antemão a multiplicidade de expressões artísticas para traduzir os anseios e as visões de mundo de cada um dos artistas não impede que o estudante se identifique mais intimamente com um deles.

Por último, e não menos importante, ao afirmar que a obra de arte admite leituras renovadas, cabe ao professor redobrar sua atenção, renunciar à omnisciência e virar aprendiz, posto que "toda relação afetiva afeta os dois termos da relação" (Katinsky, 1995), e ganha na troca, como antecipa o poeta (Camões, 1966, p. 34): "Transforma-se o amador na cousa amada/ Por virtude de muito imaginar".

\section{Referências bibliográficas}

ARTIGAS, V. Caminhos da Arquitetura. São Paulo : Lech, 1981. p. 39-50: O Desenho.

BERLIN, I. The roots of romanticism. Princeton : Princeton University Press, 1999.

BOBBIO, N. Dicionário de Política. Brasília : EdUnb, 1992.

BOTTOMORE, Tom. (Ed.). Dicionário do pensamento marxista. Rio de Janeiro : Zahar, 1988.

CAMÕES, L. V. Camões : verso e prosa. São Paulo : Paz e Terra, 1966. p. 34: Soneto 10.

CHAUÍ, M. Convite à filosofia. São Paulo : Ática, 1994.

CORBISIER, R. Enciclopédia filosófica. Rio de Janeiro : Civilização Brasileira, 1987.

COSTA, Lúcio. Arquitetura. Rio de Janeiro : Bloch, 1980. (Biblioteca Educação é Cultura).

DUROZOI, Gérard, ROUSSEL, André. Dictionnaire de Philosophie. Paris : Nathan, 1990.

GOLDMANN, L. Dialética e cultura. Rio de Janeiro : Paz e Terra, 1979. p. 29-44: O materialismo dialético é uma filosofia?

HUME, D. Ensaios morais, políticos e literários. In: BERKELEY, George. Tratado sobre os pincípios do conhecimento humano [...]; David Hume. Investigação [...]. São Paulo : Abril Cultural, 1984. p 205-327 (Coleção Os Pensadores).

KATINSKY, Júlio R. Sete proposições sobre história da Arquitetura. Revista Pos, São Paulo, p. 119-123, 1995. Edição especial.

MARX, K. A ideologia alemã. São Paulo : Gijalbo, 1977.

. Manuscritos econômico-filosóficos e outros textos escolhidos. São Paulo : Abril Cultural, 1978. (Coleção Os Pensadores).

MARX, K. Sobre literatura e arte. São Paulo : Global, 1979.

SCHILLER, F. On the aesthetic education of man. Clarendon : Oxford, 1982.

TATARKIEWICZ,W. História de seis idéas. Madrid : Tecnos, 1995.

VERNANT, J-P. Les origines de la pensée grecque. Paris : Presses Universitaires de France, 1981. 
Recebido em 29 de março de 1999.

Matheus Gorovitz, doutor pela Faculdade de Arquitetura e Urbanismo da Universidade de São Paulo (USP), é professor de História da Arte e Estética do Departamento de Teoria e História da Faculdade de Arquitetura da Universidade de Brasília (UnB).

\section{ABSTRACT}

It discourses on the need to teach art and its history on education. It aims to educate the judgement of taste so that it enables students to identify beauty as an expression of totality. It confirms the idea that the development of citzenship, artists and emancipated human beings are interrelated. It defines the terms that enables to check disciplinarity to the teaching of art in such a way that it recognizes on aesthetics the discipline that has as a subject of study the human praxis when that aims to show, through a work of art, the conjugation of subjective and objective, individual and social dimensions, in short, the human being as a whole. It places the categories already mentioned - judgement of taste, wholeness, beauty, autonomy and aesthetics. It suggests a methodology to read a work of art deduced from the concept premises.

Key-Words: aesthetics; beauty; taste; totality; autonomy; citzenship. 